\title{
ADAPTING VAT DYE AS AN ALTERNATE DYEING AGENT FOR VEGETABLE TANNED LEATHER
}

\author{
J. O. B. Boahin ${ }^{1}$, R. Steiner ${ }^{2 .}$ and J. A. Agyem ${ }^{3 .}$ \\ ${ }^{1,2}$ Department of Integrated Rural Art and Industry, KNUST, Kumasi. \\ ${ }^{3}$ Department of General Art Studies, KNUST, Kumasi.
}

\begin{abstract}
The research explores the use of vat dye, a selected dye that is available locally in the Ghanaian market in large quantities, with varied colour ranges to identify their suitability as effective colourants on vegetable tanned leather. Four different experiments were performed with vat dye, and two others were tried with suede dye. In the first experiment, a more familiar technique of applying vat dye on fabric was used; this resulted in the burning of the exposed areas of the leather. For the second experiment, a new formula was composed and applied. This experiment was subdivided into three parts where various techniques for applying dyes were used. It proved successful, thus indicating that, with proper formulation, vat dye and its accompanying agents could perform effectively on protein fibre in leatherwork, just as it does on cellulose fibre in textiles.
\end{abstract}

Keywords: Leather, Vat dye, Marbling, Pelt

\section{INTRODUCTION}

The problems encountered in the use of vegetable-based dyes on leather discourage the development of leatherwork education and application in the indigenous leather industry in Ghana. Leather articles come with limited range of colours and do not adequately meet consumer taste for leather products. According to Nguyen (2007), dyestuffs are any of a large group of chemicals almost exclusively organic in nature used for the coloring of textiles and other substances. Lewin (2007) and Allen (1971) have stated that modern industrial terminology defines a dyestuff as a product containing pure organic dye and other agents that make the product easier to handle.

According to the dyers method of classification there are direct dyes, which produce fast colours in fibres placed directly in the dye solutions, and indirect dyes, which produce fast colours only if the fibres are treated before or after dyeing. Nguyen (2007) has explained that most of these direct dyes have good fastness to light and to washing in cold and warm water but not to washing in hot water with detergents. On the other hand, indirect dyes such as vat and sulfur dyes are best used on cellulose fibres, especially, where fastness to frequent and hard washing is required. The simplest method of indirect dyeing involves pre-treating the fibre with mordants, or fixing solutions, before applying the dye solution (Allen, 1971).

Although there are many known dyes, these are not easily available on the local Ghanaian mar- 


\section{5}

kets. They are mostly foreign and have to be imported; a situation that is not favourable to Ghanaian dyers. There is therefore an urgent need to identify alternative dyestuffs that are common to the industry, and which can be prepared locally without much difficulty and at affordable prices. Vat dye is one such alternate dyestuff and it has several ranges of colour schemes. Asante (1980) and Sackey (2000) have asserted that vat dye is commonly used by small-scale tie and dye/batik fabric industries, for dyeing cotton fabric as well as large-scale textile industries in Ghana.

Vat dye is not used on collagen fibers because of the strong alkaline nature of its leucocompound solutions. It is usually applied on cellulose fibre to make it fast, especially, where frequent and hard washing is required. The dye is used after reducing it to a base-soluble form. It is then applied and regenerated into an insoluble dye by oxidation in the material. The remarkable fastness of vat dye to washing, light and chemicals, coupled with its availability on the local market makes it significant enough to be researched into to find convenient means of using it on leather.

The primary objective of this research is to identify simple methods by which vat dye, a cellulose fibre dye classified for dyeing cotton, rayon, flax, and ramie, could be used on leather alternatively. The two variables identified in this research were leather, the dependent variable, and vat dye, the independent variable. The dependent variable is the quality of the leather whiles the independent variables are the technologies and practices employed for the achievement of the final finished leather.

\section{MATERIALS AND METHODS}

This research explored the reactive dye method for dyeing leather through four different experiments: two different decorative techniques were adopted for the research; these were marbling and plain dyeing. The marbling technique was applied in two forms. Firstly, by achieving one colour effect (monochrome), and secondly by achieving two or more colour effects (polychrome). The emphasis on different methods to achieve the stated objective is necessitated by the character of the dye and this is further emphasised by Sharphouse (1963) who stated that they were very difficult to use on leather owing to the alkalinity of the vat liquor affecting the tannages. Dyes or dyestuffs as soluble compounds can be either absorbed and retained by the fiber or chemically combined with it. Dyes are generally fast-that is, they retain their colour in the fibre throughout the dyeing process and under exposure to normal wear, including sunlight, water, and detergent.

\section{Selection of Leather for Dyeing}

Sheepskin was used for the research. Due to the unpredictable shape of an animal skin or hide, leathers have irregular shapes; therefore, a perfect rectangular dimension is not attained due to this characteristic. The surface area of leather is thus measured from the widest point of its width by the longest point of its length. Again, this area is not always shaped in a perfect rectangle and two animal skins are not of exact equal sizes and shapes. The reactive dye formula for dyeing cotton fabric was experimented on leather with a single colour through the marbling technique. In pursuance of this, selected procedures were followed.

\section{Experiment 1: Reactive Dye Formula}

i) One tablespoonful (5 grams) of green vat dye, one tablespoonful (5 grams) of caustic soda and four tablespoonfuls (20 gram) of sodium hydrosulphite, were dissolved in a $150 \mathrm{ml}$ of hot water in a small sized plastic container, stirred and then allowed to cool down.

ii) A sheet of leather was rubbed in with olive oil, wetted and pounded, (the oil penetrates the fibres to soften it). This makes the leather much easier to work with and for effective penetration of the dye.

iii) A working table was covered with syn thetic leather and made ready for use. The 
wet leather was then spread on the working table and dragged to get it crumpled. (Plate 1)

iv) The dye was poured all over the crumpled leather with a plastic spoon (Plate 2). The dyed leather was then spread out for 15 minutes to enable oxidation to take place as in Plate 3 and plate 4 . The leather was observed to have burnt and hardened, and it assumed the shade of burnt sienna, instead of the expected soft, green coloured marbled leather. This formula was modified for the next experiment. The same quantities of two main

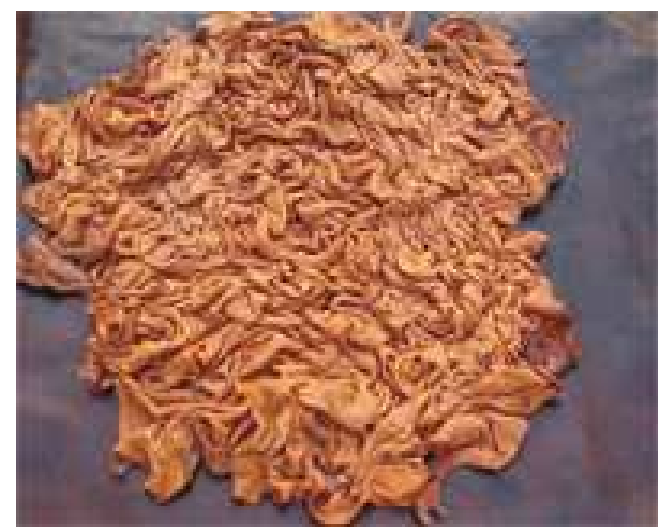

Plate 1: Crumpled leather

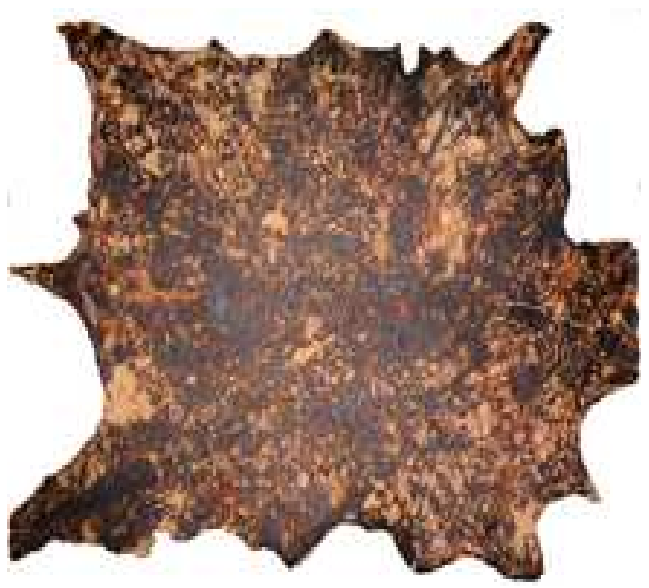

Plate 3: Marbled leather after dying auxochromes (caustic soda and sodium hydrosulphite) were tested separately on leather. It was noted that the quantity of caustic soda was more than what the leather could sustain. Therefore, in subsequent experiments as identified below, the quantity of caustic soda was reduced.

Dye marbling with a single colour (monochrome)

Dye marbling with two or more colours (polychrome)

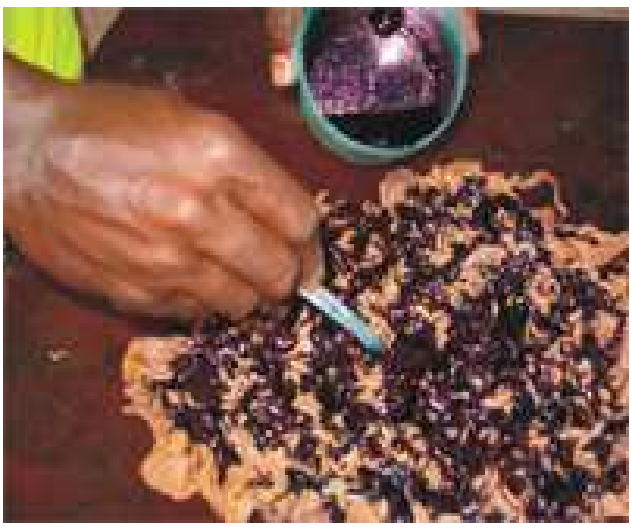

Plate 2: Pouring dyes on leather

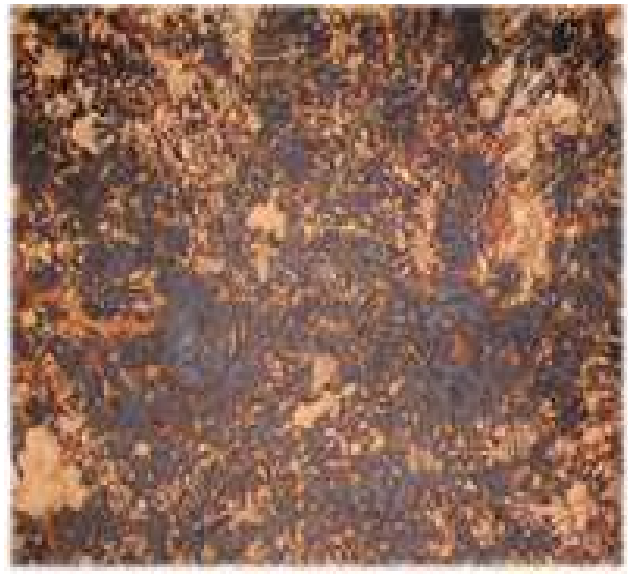

Plate 4: A closer view of the marbled leather

Journal of Science and Technology 은 KNUST August 2011 
Plain dyeing with single colour (monochrome)

Experiment 2: Comparing the Reactivity of the Auxochromes on Leather

To find out which of the two chemicals (auxochromes, i.e. caustic soda and sodium hydrosulphite) reacted negatively to cause the dark brown burns on the leather, the same quantity of each chemical was dissolved in hot water and poured into two separate containers. Two pieces of leathers were submerged in each of them for fifteen minutes to observe the reaction of the two chemicals used as auxochromes. The sodium hydrosulphite did not give any reaction, but the caustic soda burnt the piece of leather, indicating that the quantity of caustic soda as an additive was too much and needed to be reduced. Further experiments therefore became necessary.

\section{Experiment 3: Dye Marbling with a Single Colour (Monochrome)}

In this experiment, the dye solution was prepared by adding one tablespoonful (5grams) of green vat dye, half teaspoonful (2.5grams) of caustic soda, four table-spoonful (20grams) of sodium hydrosulphite to a $150 \mathrm{ml}$ of hot water. The dye solution was stirred and poured over the crumpled leather, which was then left to dry as shown in Plate 5. Plate 7 shows a closer view of the marbled leather. The same process for dyeing leather as stated in experiment one was followed, except that the quantity of caustic soda was reduced to one teaspoonful (2.5gram).. The experiment resulted in the successful use of the vat dye in the production of green marbled leather.

\section{Experiment 4: Dye Marbling with two Col- ours}

This experiment aimed at ascertaining the viability of using more than one colour. Leather was pounded in order to soften it, and then crumpled in a more regular pattern (Plate 8) as in the first experiment. Two different colours; red and green, were used to achieve a multi coloured effect (Plate 9). This was done by first pouring red colour over the crumpled leather, followed by the application of green colour.

The leather was left on the working surface for thirty minutes to allow oxidation to take place as in Plate 10, and afterwards it was rinsed in clean water to remove the excess dyes and the auxochromes. The rinsed leather was next stretched on a stretcher board to dry. Plates 11 and 12 show full sheet dye-marbled leather and a close-up view of polychromatic dye-marbled leather respectively.

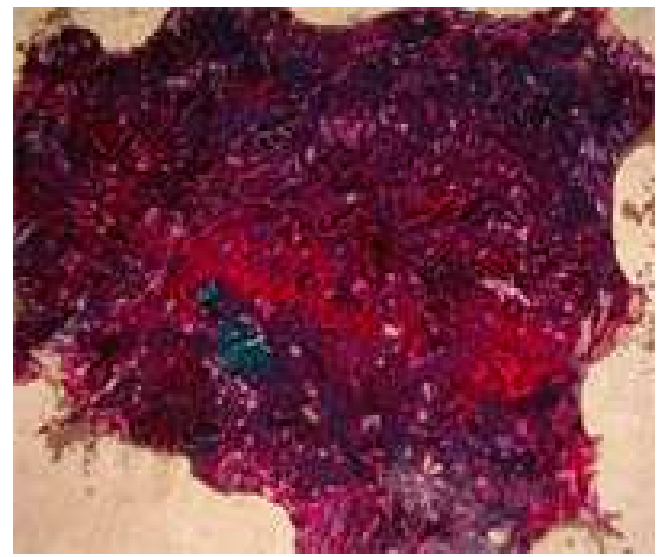

Plate 5: Crumpled leather spread out for oxidation to take place

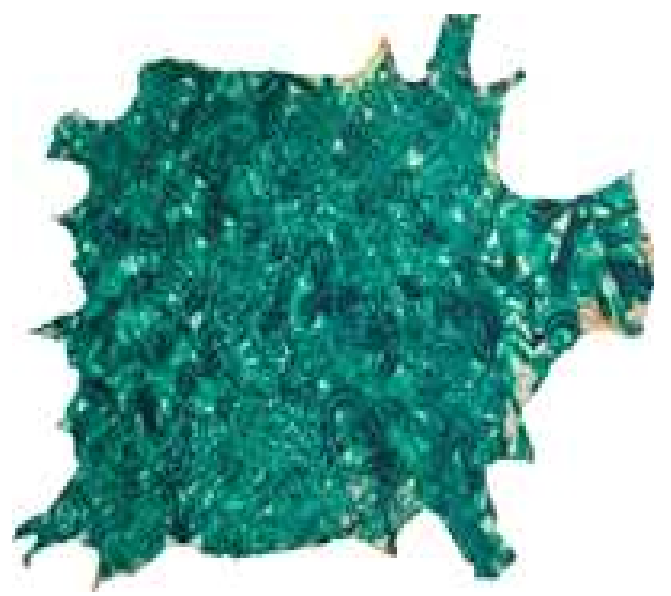

Plate 6: Marbled leather after dyeing 


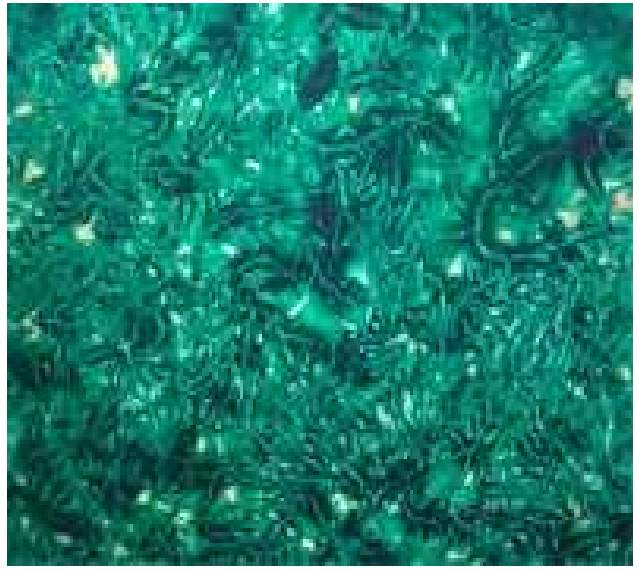

Plate 7: A closer view of the marbled leather

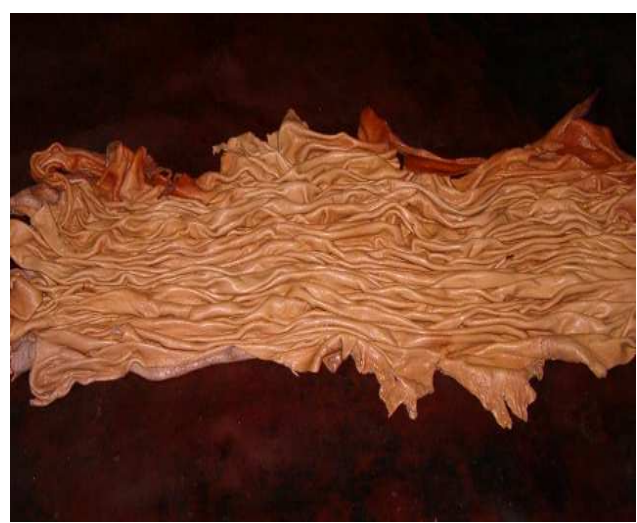

Plate 8: Leather crumpled in vertical formation

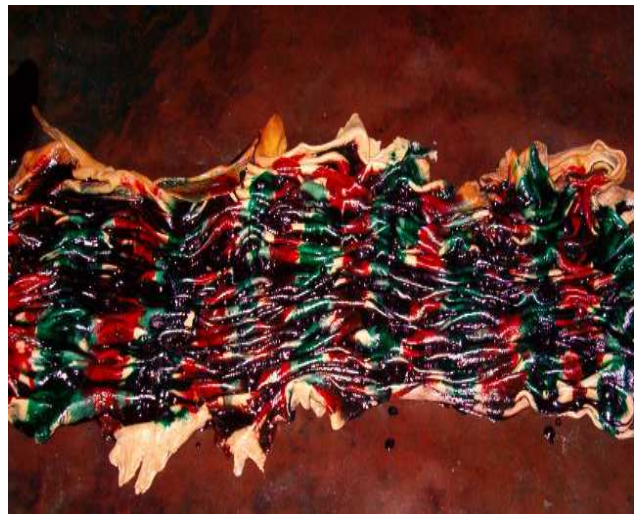

Plate 9: Red and green dyes, poured on crumpled leather

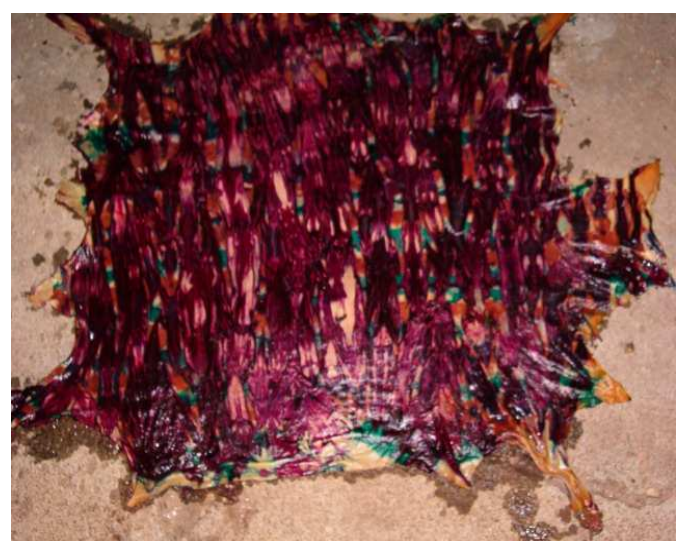

Plate 10: Dyed leather spread out for oxidation to take place

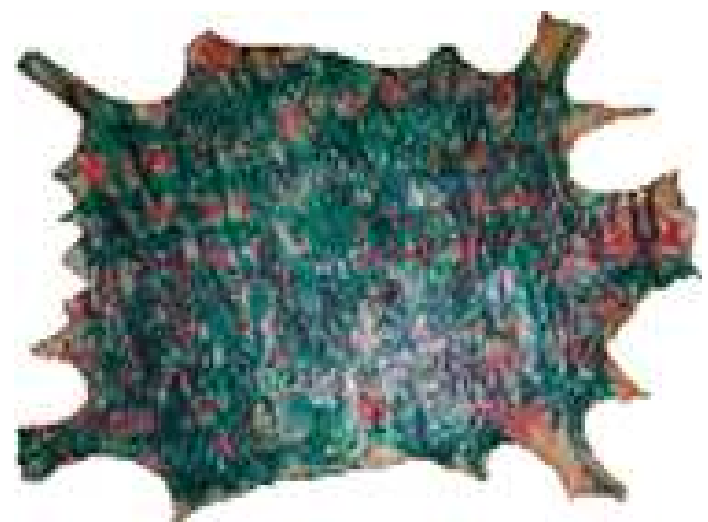

Plate 11: Full sheet dye-marbled leather

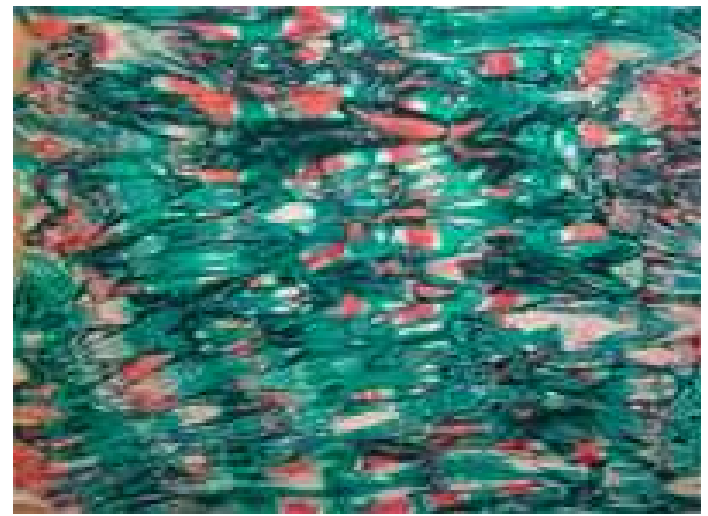

Plate 12: Closer view of dyed marbled

Journal of Science and Technology 은 KNUST August 2011 


\section{Experiment 5: Plain Dyeing (Monochrome)}

A further experiment was targeted at attaining a plain dyeing effect as follows:

i

The sheet of leather was soaked and pounded in a mortar with pestle to soften it as explained earlier.

ii The dyed solution was prepared by mixing one tablespoonful (5 grams) of green vat dye one tablespoonful (2.5 grams) of caustic soda and four tablespoonful (20grams) of sodium hydrosulphite in 200 litres of hot water and stirred, it was then left to cool down.

iii Three litres of clean lukewarm water was poured into an eight litre plastic container. The prepared dye solution was poured into the lukewarm water and stirred thoroughly to mix. The leather was immersed in the mixed solution and was turned over for five minutes before being submerged in the solution for about ten minutes. At the end of fifteen minutes, it was removed and spread out in the open air for oxidation to take place. The leather was afterwards rinsed in clean water and then stretched out on a stretcher board for drying. The process was repeated where a deeper shade was required.

iv The dried leather was burnished at the grain surface to give it a shiny and smooth surface value. It also helped to soften the leather as it broke up the compressed fibres.

\section{RESULTS AND DISCUSSION}

Knowledge of the structure of leather is essential for the leather-dyers to understand the intrcate character of the connective tissues that constitute the material, and then determine dyes and auxochromes that can best be used on leather without disturbing its surface value (O'Flaherty et al., 1962).
According to Kite and Thomson (2006), the unique characteristics of leather are due largely to its structure, which is an interwoven, threedimensional network of fibres inherent in the natural raw materials-hides and skins. This raw material is principally a fibrous protein called collagen and is composed of one continuous network of fibres. This character of leather necessitates the identification of appropriate locally available dyes and auxochromes capable of penetrating the fibres without disturbing their natural properties such as flexibility, tensile strength, pliability, as well as utility. It has also been explained by Sharphouse (1995), Bienkiewicz (1983) and Sarkar (2005) that the mammalian hides and skins are divided into three layers distinct in structure and origin. Starting from the outside, these are: (1) A thin outer layer of epithelial cells, called the "epidermis"(1\% of total thickness), (2) A thick layer called the corium, or dermis (85\%), (3) A subcutaneous layer or adipose tissue known as 'flesh' (14\%). The dermis is used to make leather after the two sandwiching layers have been removed.

Leather can only be dyed after tanning; this is unlike textiles, where materials can be dyed at any stage in their manufacturing process, with fibers also being dyed and then woven into patterned fabrics or solid-colored clothes. Coloured designs can also be made on woven cloth by several processes. The dyeing process required the use of relevant chemical additives, known as auxochromes, which have the property of anchoring the desired dye effectively; they are acidic or basic and give rise to acid and basic dye salts. In the case of leather, the protain nature of the fibres require the manipulation of the appropriate auxochromes in order to realise the dyestuff's suitability as colourant for leather. This was realized as the reactive dye formular for dyeing cotton fabric as in textiles did not prove useful on leather, since its effect was negative. In the first experiment, the areas of the leather that should have dyed green, instead, burned to a shade of burnt sienna. To 
find out which of the two chemicals (auxochromes, i.e. caustic soda and sodium hydrosulphite) reacted negatively to cause the dark brown burns on the leather, the same quantity of each chemical was dissolved in hot water and poured into two separate containers. Two pieces of leather were submerged into the containers for fifteen minutes. The sodium hydrosulphite did not give any reaction but the caustic soda burnt the piece of leather indicating that the quantity of caustic soda as an additive was too much and needed to be reduced. Further experiments therefore became necessary.

In the subsequent experiments, the quantity of caustic soda was reduced by half $(50 \%)$, and the result was that, green coloured marbled leather was produced without any burns. The excess dyes were thoroughly washed off with clean water leaving clean dyed leather that did not bleed. This test therefore indicated that vat dye could be used on protein fibres contrary to the assertion made by Lewin, (2007); that vat dye as a cellulose dye cannot be used on protein fibres.

The strong alkaline nature of the cellulose fibres leuco-compound solutions requires to be manipulated to make it useful on leather. The assertion that these dyes perform best on cellulose fibres, especially where speeding up of frequency and hard washing is required, and this has been found to be equally applicable to leather, where penetration of dyes into fibers has been equally achieved. By its character, dyestuffs must be capable of entering and colouring fibres or other substances, and the auxochromes, have the property of anchoring the desired dye effectively.

The successful application of vat dye on leather with a single colour made it easier to succeed with multicolour application in the subsequent experiment with two colours, thus expanding the choice of colour schemes for decorating leather. The result was tested when selected leatherworkers and students used the new tech- nique to dye some leathers and thereafter produced variety of leather articles as indicated in Plates 13 and14. Currently, many leatherwork practitioners are using the vat dye as colourant on leather to enhance the value of their products.

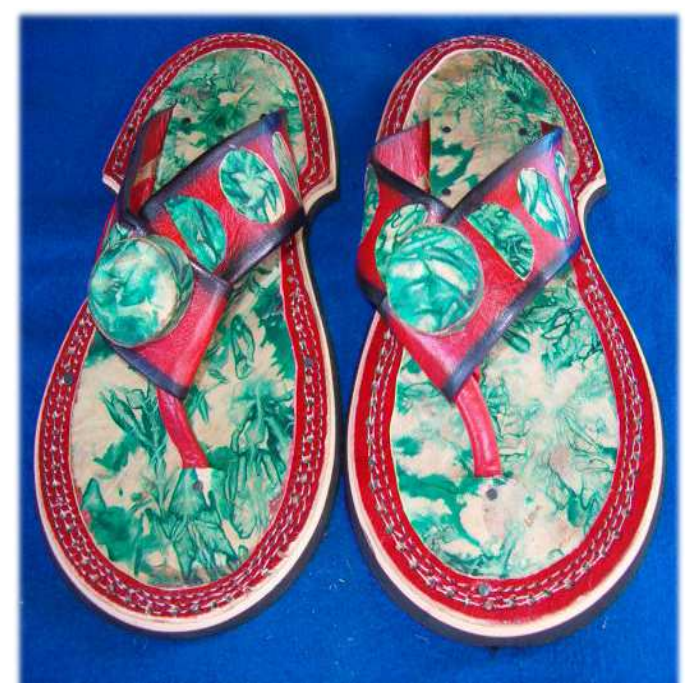

\section{Plate 13: Ghanaian traditional sandals} (Ahenema)

Further application of vat dye on leather through the 'plain dyeing' technique revealed that the grain side of the leather could not absorb the dye as expected; the dye was more intense and brilliant on the flesh side which is more fibrous than the grain side, that has highly compressed fibers. The compressed fibres reduce the auxochromes ability to anchor the dyes to the desired effect as done on the fibrous side. Further examination of the application of vat dye, through the 'marbling' and 'plain dyeing' techniques indicated that, vat dye's colour intensity is achieved only when there is concentration of dye solution on the part of the leather being dyed. In its broadest sense, the research has proven that leather, as a substance that can absorb dyestuffs, and that, research to identify alternative methods of application is necessary to the benefit of the industry. As a soluble compound, the vat dye was perfectly absorbed and 


\section{Boahin et al.}

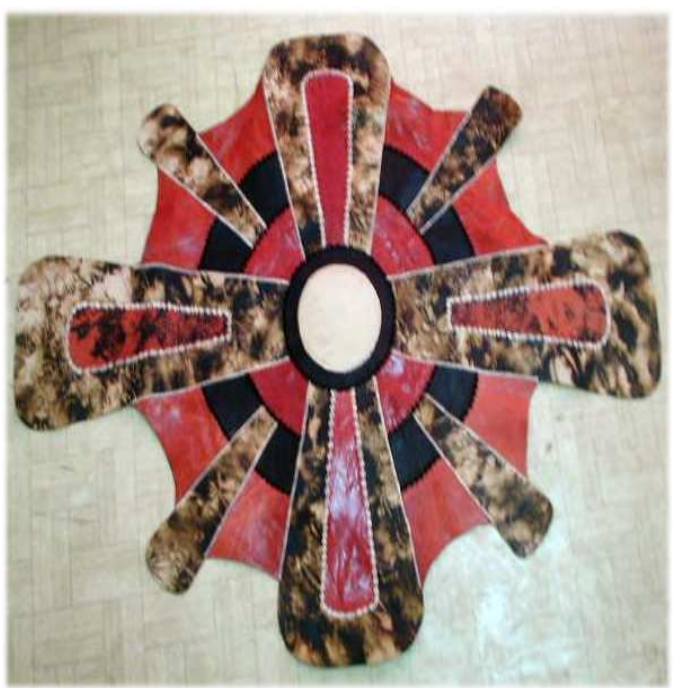

Plate 14: Table mat

retained by the fibres of the leathers; the colouring matter became an integral part of the fibres. Although it has been emphasized by Bienkiewicz (1983), Sharphouse (1995) and Sarkar (2005) that by its character the grain side of leather has highly compressed fibres in contrast to the flesh side (fluffy side). Therefore, to achieve effective colouration, penetration and a more permanent bonding required between the collagen fibres of leather and vat dye, it is a prerequisite to manipulate the auxochromes of the dye to a suitable quantity and also manipulate the fibres of the leather to open up through pounding.

\section{CONCLUSION}

The expanding taste for quality and aesthetically appealing leather goods in this economically competitive era requires the promotion of innovations in the indigenous leather industry. It is in view of this, that the research was conducted to ascertain the possibility of using vat dye as an alternate colourant on leather. To accomplish the stated objective, different experiments were performed, whereby vat dye and its auxochromes were tried on leather in different forms, before acceptable methods were achieved. The dye was able to penetrate the fibers and establish firm bond, which thus made it permanent and did not bleed when washed or fade when exposed to sunlight. Indeed, the experiment has substantiated that dyestuff must be capable of entering and colouring fibres or other substances, and this has been proven by the selection and effective application of vat dye, a locally available dyestuff, as a colourant for leather. The result of this research will help in infusing innovation into the teaching and production of leather goods in variety of colours to compete effectively with other goods on the local and international markets.

\section{REFERENCES}

Allen, R. L. M. (1971). Colour Chemistry Studies in Modern Chemistry; Apapa, Lagos. Thomas Nelson (Nigeria) Ltd.

Asante, C. (1980). Textile for Senior Secondary Schools and West African Colleges; Kumasi. New Era Ltd.

Bienkiewicz, K. (1983). Physical Chemistry of Leather Making. Malabar, Florida: Robert E. Krieger Publishing Company.

Kite, M. and Thomson, R. (2006). Conservation of Leather and Related Materials. Elsevier Ltd. London.

Lewin, S. Z. (2007). "Dyestuffs." Microsoft Student 2008 [DVD]. Redmond, WA: Microsoft Corporation.

Nguyen, H. X. (2007). "Dyeing”. Microsoft Student 2008 [DVD]. Redmond, WA: Microsoft Corporation.

O'Flaherty, F., Roddy, W. T. and Lollar, R. M. (1962). The Chemistry and Technology of Leather, Vol.III-Control of Leather Quality. Florida: Krieger Publishing Company.

Sackey, S. K. (2000). Textiles for Schools and Colleges; Accra. Ask Publications. 
Adapting vat dye as... $\quad 82$

Sarkar, K. T. (2005). Theory and Practice of Leather Manufacturing. Kolkata: Neelachal Abasan Bishaka A.1, and ACP Publications.
Sharphouse, J. H. (1995). Leather Technician's Handbook, LPA 75th Anniversary Edition. Northampton, UK: Leather Producers' Association. 